\title{
The Design of Digital Heart Rate Meter Using Microcontroller
}

\author{
Tatiya Padang Tunggal ${ }^{1}$, Shela Asta Juliani ${ }^{2}$, Hendro Agus Widodo ${ }^{3}$, Rachmad Andri Atmoko ${ }^{4}$, Phong Thanh \\ Nguyen $^{5}$ \\ 1, 2 Department of Electrical Engineering, Universitas Muhammadiyah Yogyakarta, Yogyakarta, Indonesia \\ ${ }^{3}$ Politeknik Perkapalan Negeri Surabaya, Surabaya, Indonesia \\ ${ }^{4}$ School Of Mechanical and Electrical Engineering, Guilin University of Electronic Technology, China \\ ${ }^{5}$ Director, Department of Project Management, Ho Chi MinhCity Open University, Vietnam \\ tatiyapt@umy.ac.id, shela_asta_juliani@umy.ac.id, hendro.aw@ppns.ac.id,mokoraden@hotmail.com, \\ phong.nt@ou.edu.vn
}

\begin{abstract}
Cardiac tests generally use an electrocardiograph, the results of which are used by medical teams to diagnose heart conditions. Individual ECG examination is held in a health care institution so that it cannot be held independently, considering the high costs and the need for analysis by a specialist. It is, therefore, necessary to have a functional and portable device to detect heart rate. The heart rate measuring device, equipped with a finger sensor, was designed for adults. The 15-second measurement interval showed the heart rate in one minute and the results were shown on an LCD. The minimum system circuit used ATMega 16.
\end{abstract}

Keywords - heart rate, beat per minute, microcontroller

\section{INTRODUCTION}

The health condition of a person may change at any time if it is not properly controlled and maintained. Similarly, people who have a healthy body can also potentially be affected by the disease, one of which is the heart organ. Efforts required to maintain health as the first step to prevent heart disease is knowing the number of heartbeats in normal or abnormal conditions.

BPM is the number of heartbeats in one minute. The normal pulse for healthy adult ranges from 60 to 100 BPM. Bradycardia occurs when the pulse rate is less than 60 per minute, while tachycardia occurs when the heart rate is more than 100 BPM. The working principle of this diagnostic device is to calculate the number of heartbeats in minutes. The heart rate will determine whether the patient's heart condition is normal or not.

Some researchers have researched heart rate. Biniyam designed and implemented heart rate monitoring using a PIC microcontroller. The project used an infrared sensor and a photodiode detector that monitored the heart rate and LM358 to process signals [1]. Mahmood developed a wireless body area network to monitor patients' health remotely. The detection of fall used various sensors, including electrocardiography (ECG), temperature, and accelerometer [2]. Turner utilized a smartphone to monitor heart rate. The AD8232 Single Lead Heart Rate Monitor was the main part of the design [3]. Sosa designed a wireless heartbeat monitor operated without batteries. This design was based on commercial ultra-low-power microcontrollers, optimized custom full front-end RF, ultra-low-power threshold comparison, and programmable amplifiers implemented in $90 \mathrm{~nm}$ commercial CMOS [4]. Tjiharjadi created the application of the Human Heart Rate Detection applying IoT technology to measure the human heart rate monitored using gadgets [5]. Pawar used Arduino Uno for a heart rate monitoring system based on an IR sensor. The system consisted of IR-based heart rate sensors, Arduino Uno, and GSM modules [6]. Priya implemented a wireless technique for real-time monitoring of vital signs. The design of a portable wireless ECG system used for remote monitoring of cardiac activity is one of the most important fields of telemedicine and telecare [7]. Mansor studied portable heart rate measurements for remote health monitoring systems. The main components of this project were pulse sensors, microcontrollers (Arduino with Ethernet shields), and wireless communication devices (Xbee) [8]. Heart rate measurements using photoplethysmography was studied by Saquib. The method used to measure heart rate in this project was widely known as photoplethysmography (PPG) [9]. Lee studied and implemented low-cost automatic blood flow control devices via smartphones for biomedical applications based on microcontrollers [10].

Hodge investigated Wireless Heart Rate Monitoring and the Vigilant System, which aimed at bringing a cheaper and more efficient system to monitor heart rate [12]. Gobhinath S. designed and examined a GSM automatic driver sleepiness warning system. When the driver was asleep, the vehicle stops and monitors the heart rate, breathing rate, and dry temperature of the driver and then displayed it on the computer [13]. Nature studied a portable photoplethysmogram acquisition and analysis device. It was an acquisition of simple PPG and early-level analysis tools using laptops [14]. Megalingam investigated an HDL-based controller for a continuous monitoring system of multiple vital health parameters for recording. He monitored various parameters, including heart rate, temperature, pressure, blood oxygen levels, sugar levels, etc. [15].

Natumploy used an Arduino microcontroller in a portable ECG display for experimental learning through a senior 
design project. Bishnu studied a Heart Rate Monitoring System using the IR photodetector sensor [17]. Lichtman studied the Intelligent Electrocardiogram Monitoring System on Android. Because the commercial electrocardiogram system on the market was not an open-source platform, this work presented a smart system structure measuring biosignal, transfers data via Bluetooth, displays real-time electrocardiogram, and body temperature on cellphones that supported Android and warned users with caution [18]. Design and implementation of Low-Cost Blood Pressure Measurement Devices researched by Ali. Manual measurement using a Stethoscope and Sphygmomanometer was the most accurate and inexpensive method of BP measurement [19]. Purwiyanti examined the Multisensor System for Real-Time Detection of the Length, Weight, and Heartbeat of Premature Babies in the Incubator. The incubator can also measure the length and weight of a baby automatically using an ultrasonic sensor and a load cell sensor [20].

The objectives of making this system are (a) to provide good software accuracy, (b) to ensure proper work of the total system operation, and (c) to make a program, used to examine the heart condition by measuring the heart rate.

\section{METHOD}

The finger sensor [21] detects the flow of blood that passes through the index finger, the infrared light [22] - [24] that emits is reflected by the eye, and the light is captured by the Photodiode [17], [25] as described in figure 1.

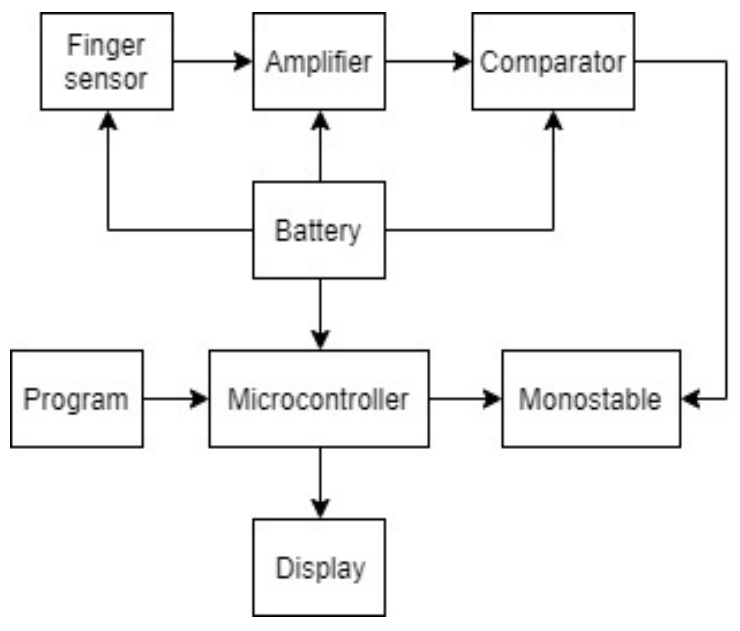

Fig. 1. System block diagram

Heartbeats affected the pressure of the blood, resulting in a signal. The signal obtained by the sensor would be afterward transmitted to the Amplifier circuit and filtered to make the real heart rate signal visible. After filtering, the signal obtained was still low and would be reinforced for a comparison. When the signal reached the comparator block, it was compared to the reference voltage. After compared, the signal would be activated by the Monostable signal, which generated a logical signal. Monostable was an input to be processed from the IC Microcontroller. The results shown on the data display would be stored [26] - [30].

A. System work flow
The system workflow is shown in Figure 2. First, Initialization starts the software and initializes the LCD. The LCD is programmed by the microcontroller before it runs the program. Counting the heart rate to begin to monitor it and Saving the data are the next steps. Reset EEPROM functions to erase the saved data, while Reset to repeat the program. Finish tells that the plan has been complete.

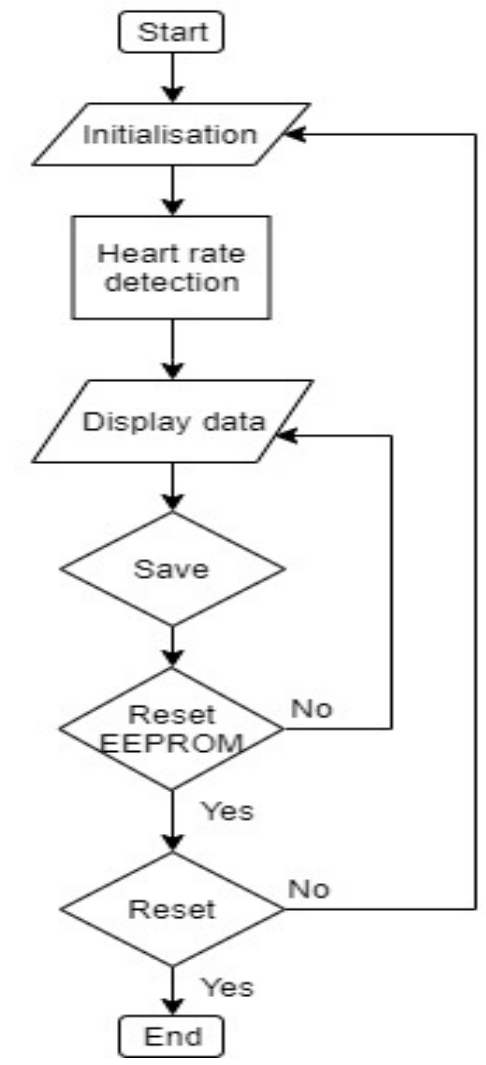

Fig. 2. System work flow diagram

\section{B. System hardware}

The minimum system as it is shown in Figure 3 consists of several components, namely the ATMega16 microcontroller interface circuit with an external oscillator, the button interface circuit for program work processes, and the LCD interface circuit used to display measurement data.

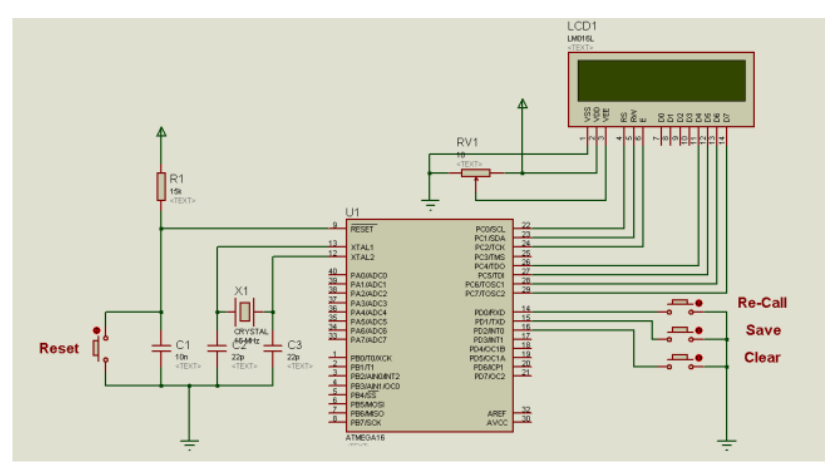

Fig. 3. Minimum system schematic

\section{Measurement systematic}

Voltage measurements at several test points were performed several times during the experiment. The 
measurement results were afterward compared to the standard numbers and some average values and errors.

\section{IMPLEMENTATION}

The next step after creating the module was testing and measuring. The author collected the data through several phases of the measurement and testing process, which aimed to determine the density of the module production and to ensure that each part of the entire set of modules had worked as planned.

The steps to measure and test the module were first, preparing the devices needed, especially the measuring module and comparison device, second, the making a table to present the measurement results, third, testing the module by conducting BPM measurements on SP02 and writing the results of the measurements and calculations in the table provided. Finally, computing the measurement results to determine the level of error, the average, and the standard deviation

In measuring the BPM, the author compared the pulse oximetry device, already feasible to use with the module device designed. The calibrator and comparator were with the specifications of (a) brand: Huge Industry, AH-50D, (b) type: Fingertip Pulse Oximeter.

TABLE I. Average AND ERror ObTAINED

\begin{tabular}{|c|c|c|}
\hline No. of patient & Average & Error \\
\hline 1 & 74.6 & $0,03 \%$ \\
\hline 2 & 74 & $0,03 \%$ \\
\hline 3 & 72.8 & $0,04 \%$ \\
\hline 4 & 76.8 & $0,05 \%$ \\
\hline 5 & 71.6 & $0,02 \%$ \\
\hline 6 & 82 & $2,84 \%$ \\
\hline 7 & 85 & $0,02 \%$ \\
\hline 8 & 78.2 & $0,01 \%$ \\
\hline 9 & 80 & $0,03 \%$ \\
\hline 10 & 86.8 & $0,01 \%$ \\
\hline 11 & 80 & $0,03 \%$ \\
\hline 12 & 86.8 & $0,01 \%$ \\
\hline 13 & 75,6 & $0,03 \%$ \\
\hline 14 & 85.2 & $0,04 \%$ \\
\hline 15 & 83.6 & $0,02 \%$ \\
\hline 16 & 79.4 & $0,04 \%$ \\
\hline 17 & 74.6 & $0,03 \%$ \\
\hline 18 & 73.4 & $0,02 \%$ \\
\hline 19 & 73 & $0,02 \%$ \\
\hline 20 & 76.8 & $0,06 \%$ \\
\hline
\end{tabular}

In the measurement of the BPM, the authors compared the model device to the standard pulse oximetry. The calibrator and the comparator comply with the specifications of (a) brand: Huge Industry, AH-50D, and (b) type: Fingertip Pulse Oximeter. The advantages of the device include portable, rechargeable power supply, ease of use, and relatively accurate results. The disadvantages of this device include no indicator when the battery capacity was weak and applicable to adults only.

\section{CONCLUSION}

After a process of designing, experimenting, testing, and data collecting, the author concludes that the heart rate detector works properly according to the experimental results on several patients compared to standard medical devices. The device's minimum system circuit works properly as it controls and displays the BPM measurement results. The finger sensor circuit shows satisfactory results in the detection of heart rate.

\section{REFERENCES}

[1] A. Biniyam, A. G. Tesema, A. A. Mohammed, N. S. Ramaiah, and A. E. Dilla, "Design and implementation of heart beat monitoring using PIC microcontroller," in 2017 International Conference On Smart Technologies For Smart Nation (SmartTechCon), 2017, pp. 784-787.

[2] A. S. Mahmood, E. Jafer, S. Hussain, and X. Fernando, "Wireless body area network development for remote patient health observing," in 2017 IEEE Canada International Humanitarian Technology Conference (IHTC), 2017, pp. 26-31.

[3] J. Turner, C. Zellner, T. Khan, and K. Yelamarthi, "Continuous heart rate monitoring using smartphone," in 2017 IEEE International Conference on Electro Information Technology (EIT), 2017, pp. 324-326.

[4] J. Sosa and H. Solar, "Design of a wireless and batteryless heart rate monitor," in 2017 IEEE 60th International Midwest Symposium on Circuits and Systems (MWSCAS), 2017, pp. 1292-1295.

[5] S. Tjiharjadi and A. Fajar, "Human Heart Rate Detection Application," in 2017 International Conference on Soft Computing, Intelligent System and Information Technology (ICSIIT), 2017, pp. $167-172$.

[6] P. A. Pawar, "Heart rate monitoring system using IR base sensor \&amp;amp; Arduino Uno," in 2014 Conference on IT in Business, Industry and Government (CSIBIG), 2014, pp. 1-3.

[7] L. Priya, R. Hariprasad, and R. Raghul, "Real time monitoring of vital signs using wireless technique," in 2014 International Conference on Green Computing Communication and Electrical Engineering (ICGCCEE), 2014, pp. 1-7.

[8] H. Mansor, S. S. Meskam, N. S. Zamery, N. Q. A. M. Rusli, and R. Akmeliawati, "Portable heart rate measurement for remote health monitoring system," in 2015 10th Asian Control Conference (ASCC), 2015, no. June 2013, pp. 1-5.

[9] N. Saquib, M. T. I. Papon, I. Ahmad, and A. Rahman, "Measurement of heart rate using photoplethysmography," in 2015 International Conference on Networking Systems and Security (NSysS), 2015, pp. 1-6.

[10] M. S. Ali and M. H. Bhuyan, "Design and implementation of a lowcost automated blood flow control device through smart phone for bio-medical application," in 2017 6th International Conference on Informatics, Electronics and Vision \& 2017 7th International Symposium in Computational Medical and Health Technology (ICIEV-ISCMHT), 2017, pp. 1-5.

[11] E. Susana and H. Tjahjadi, "Handheld pulse oximeter based on single board computer raspberry Pi B +," in 2017 15th International Conference on Quality in Research (QiR): International Symposium on Electrical and Computer Engineering, 2017, pp. 141-145. 
[12] A. Hodge, H. Humnabadkar, and A. Bidwai, "Wireless Heart Rate Monitoring and Vigilant System," in 2018 3rd International Conference for Convergence in Technology (I2CT), 2018, pp. 1-5.

[13] Gobhinath S., Aparna V, and Azhagunacchiya R, "An automatic driver drowsiness alert system by using GSM," in 2017 11th International Conference on Intelligent Systems and Control (ISCO), 2017, pp. 125-128.

[14] S. Alam and R. Gupta, "Portable photoplethysmogram acquisition and analysis instrument," in 2016 2nd International Conference on Control, Instrumentation, Energy \& Communication (CIEC), 2016, pp. $178-182$.

[15] R. K. Megalingam, G. Pocklassery, P. S. Teja, S. V. Reddy, and K. S. Kumar, "HDL based controller for continuous multiple vital health parameters monitoring system for record keeping," in 2016 10th International Conference on Intelligent Systems and Control (ISCO), 2016, pp. 1-5.

[16] S. Natumploy, R. Sophrom, and D. Bunnjaweht, "Portable ECG Display: An Experiential Learning through a Senior Design Project," in 2018 11th Biomedical Engineering International Conference (BMEiCON), 2018, pp. 1-4.

[17] S. K. Bishnu et al., "Heart Rate Monitoring system using IRphotodetector sensor," in 2018 IEEE 9th Annual Information Technology, Electronics and Mobile Communication Conference (IEMCON), 2018, pp. 914-917.

[18] A. Lichtman, R. Uzsak, M. Svetlak, and P. Fuchs, "A Smart Electrocardiogram Monitoring System on Android," in 2018 New Trends in Signal Processing (NTSP), 2018, pp. 1-5.

[19] M. S. Ali and M. H. Bhuyan, "Design and Implementation of a LowCost Blood Pressure Measuring Device," in 2018 10th International Conference on Electrical and Computer Engineering (ICECE), 2018, pp. 309-312.

[20] S. Purwiyanti, S. R. Sulistiyanti, F. A. Setyawan, B. M. Wibisono, K. sasmita Atmaja, and H. Fitriawan, "Multisensors System for Real Time Detection of Length, Weight, and Heartbeat of Premature Baby in The Incubator," in 2018 International Conference on Electrical Engineering and Computer Science (ICECOS), 2018, vol. 17 , pp. $85-88$.

[21] S. S. Mohammedsheet and M. S. Aziz, "Design and implementation of digital heart rate counter by using the 8051 microcontroller," in
2018 International Conference on Engineering Technology and their Applications (IICETA), 2018, pp. 107-111.

[22] S. J. Gurr, J. Goleski, F. P. Lima, R. Seabra, C. J. Gobler, and N. Volkenborn, "Cardiac responses of the bay scallop Argopecten irradians to diel-cycling hypoxia," J. Exp. Mar. Bio. Ecol., vol. 500, no. August 2017, pp. 18-29, 2018.

[23] C. Aguilar, M. Ghamari, and H. Nazeran, "Development of Mobile Apps for Wireless Sensor Data Acquisition and Visualization of Biopotentials," in 2016 32nd Southern Biomedical Engineering Conference (SBEC), 2016, pp. 103-103.

[24] J. A. C. Patterson and G.-Z. Yang, "Ratiometric Artifact Reduction in Low Power Reflective Photoplethysmography," IEEE Trans. Biomed. Circuits Syst., vol. 5, no. 4, pp. 330-338, Aug. 2011.

[25] N. Sutar, M. Parihar, R. Ijare, and K. Gowari, "Design and development of SMD based wearable pulse oximeter," in 2016 International Conference on Communication and Signal Processing (ICCSP), 2016, pp. 1812-1816.

[26] C.-T. Chu, C.-C. Ho, C.-H. Chang, and M.-C. Ho, "Non-invasive optical heart rate monitor base on one chip integration microcontroller solution," in 2017 6th International Symposium on Next Generation Electronics (ISNE), 2017, no. 99, pp. 1-4.

[27] A. Noack, R. Poll, and W.-J. Fischer, "Wave sequence based identification of sinus rhythm beats on a microcontroller," in Computing in Cardiology 2014, 2014, vol. 41, no. January, pp. 337340 .

[28] M. Pandiaraj et al., "A cost-effective volume miniaturized and microcontroller based cytochrome c assay," Sensors Actuators, A Phys., vol. 220, pp. 290-297, 2014.

[29] N. Akhter, S. Tharewal, H. Gite, and K. V Kale, "Microcontroller based RR-Interval measurement using PPG signals for Heart Rate Variability based biometric application," in 2015 International Conference on Advances in Computing, Communications and Informatics (ICACCI), 2015, pp. 588-593.

[30] C.-C. Sun, K. Chun, T. T. Thai, and Y.-W. Yang, "Low-power microcontroller solution for measuring HBR using single reflection SpO2 Sensor," in 2015 IEEE International Conference on Consumer Electronics - Taiwan, 4893, pp. 82-83. 